\title{
The Protective Effect of Thyroidectomy and Ovariectomy on Experimental Liver Lesion
}

\author{
By \\ J. Kulcsár-Gergely, A. Kulcsár and I. Dévényi \\ From the Department of Pharmacology, (Director: T. Vályi-Nagy), Ist Medical, \\ Clinic (Director: B. Fornet) and Department of Pathology (Director: $P$. \\ Endes) of the Medical University in Debrecen, IIungary
}

(Received for publication, July 17, 1964)

\begin{abstract}
Sixty-five rats were thyroidectomized and ovariectomized at the same time. After this we performed liver lesion with $\mathrm{CCl}_{4}$ according to Kaufmann. The livers of these animals were compared with the livers of those treated similarly but with intact endocrine system. A light fibrosis was noted in the livers of the former group while in the latter there was a regular development of eirrhosis. Therefore a previous thyroidectomy and ovariectomy served to protect the liver from $\mathrm{CCl}_{4}$ damage.
\end{abstract}

In our earlier investigations we have dealt with the reduced estrogen sensitivity in hypothyrosis ${ }^{1)}$. This reduced estrogen sensitivity can be also found if we poison the liver of hypothyroid animals with $\mathrm{CCl}_{4}$ and after we make estrogen loadings ${ }^{2}$. Furthermore we have come to the conclusion that the thyroidectomy has a certain liver-protecting effect, which is favorably increased by an ovariectomy performed at the same time. In hypothyroid spayed rats small and medium dosages of oestrogens do not provoke oestrus at all. Large dosages have only a temporary effect and only in some of the animals.

\section{MATERIALS AND METHODS}

In our present experiments we have investigated the effect of $\mathrm{CCl}_{4}$ poisoning in such animals that have been previously thyroidectomized and ovariectomized. On 65 rats weighing 180-200 g we performed at the same time thyroidectomy and ovariectomy under ether anesthesia. Six weeks after the operation we made liver lesion with $\mathrm{CCl}_{4}$ according to Kaufmann ${ }^{3}$. At the same time we began the $\mathrm{CCl}_{4}$ treatment in 33 rats with functioning thyroid and ovaries. In pharmacological experiments we found that the liver of the operated animals decomposes faster the exogenous estrogens than in the presence of healthy thyroid and ovaries.

We made histological sections from the liver of thyroidectomized and ovariectomized rats after $\mathrm{CCl}_{4}$ treatment and compared them with sections 
obtained from the liver of control rats which had functioning ovaries and thyroids and had received only $\mathrm{CCl}_{4}$ treatment.

\section{RESULTS}

Microscopically in the thyroidectomized and ovariectomized rats after $\mathrm{CCl}_{4}$ treatment the normal architectural arrangement of hepatic lobules are well preserved. The portal spaces are slightly enlarged, sometimes they are star-like because of slender prolongations of their connective tissue substance (Fig. 1). But these prolongations are not in touch with those of other portal spaces. The arrangement of hepatic cells are regular; occasionally they show variations in size. Degenerative changes are not visible.

Summarized: Slight traces of injury are left in the form of light fibrosis and regenerative processes of the hepatic cells. A nearly complete restoration to a normal appearance.

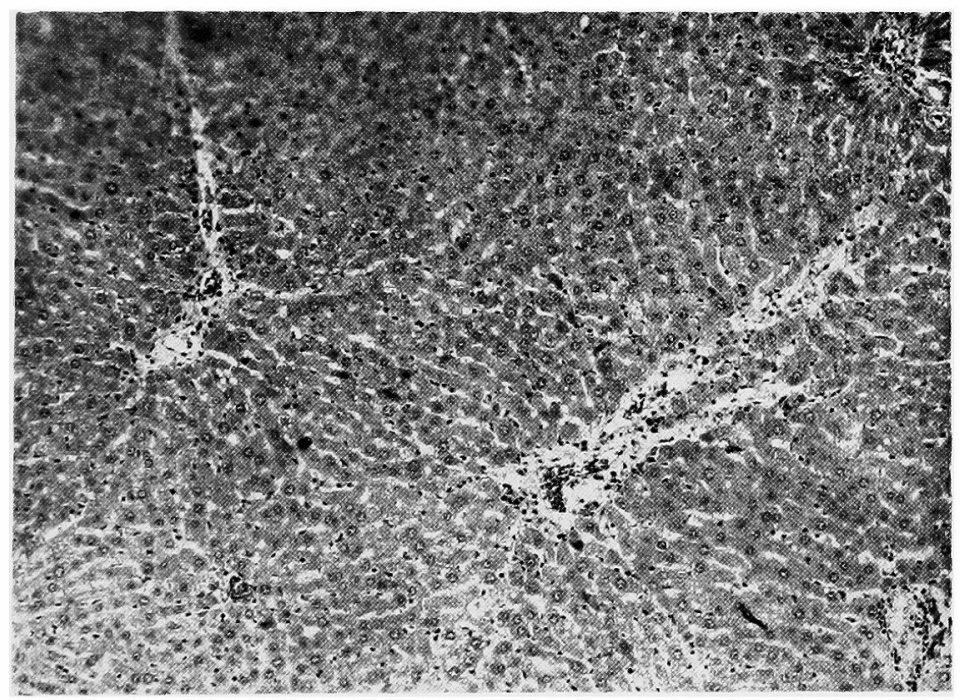

Fig. 1.

In the group treated only with $\mathrm{CCl}_{4}$ the connective tissue of the Glisson capsule is proliferated, perihepatic adhesions are evident. Bands of connective tissue divide the hepatic cells into irregular lobules of variable size. The connective tissue is young, loose, edematous, cellular and actively proliferating. Hepatic cells show great variety in size and variable degrees of fatty and hydropic degeneration (Fig. 2).

Summarized: Progressive hepatic cirrhosis. 


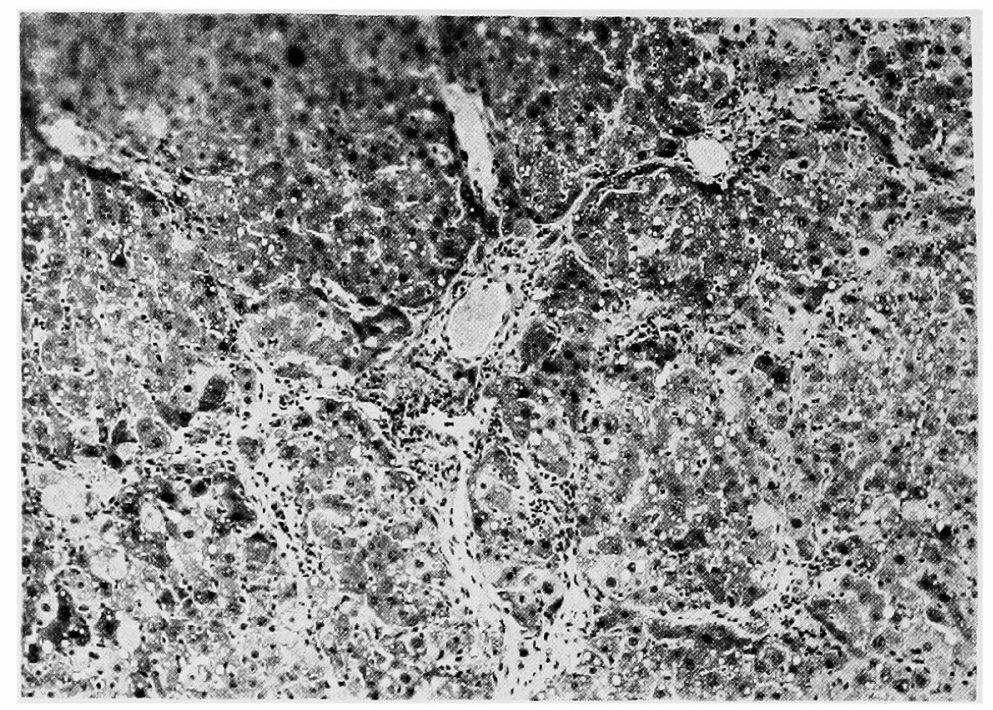

Fig. 2.

\section{DISCUSSION}

The correlations between the endocrine system and the liver have been known for some time. The liver binds, transforms, inactivates the hormones and the hormones also have certain effects on the liver. The liver is one of the target organs of thyroxine. The influence of hormones on the liver is specially important if the liver is impaired and its functional activity is limited. According to our own examinations the liver plays a part in the regulation of thyroid-ovary relationship owing to the adjustment of circulating hormones ${ }^{1,4}$.

In our present work we have investigated how the liver reacts on experimental liver injury in the lack of the thyroid and ovaries. Our results prove that in the presence of functioning thyroid and ovaries the $\mathrm{CCl}_{4}$ is capable of poisoning the liver. The previous removal of the two glands gave protection against experimental liver lesion. Cirrhosis was not noticed but only a light fibrosis was seen in the liver.

\section{References}

1) Kulcsár, A. \& Kulcsár-Gergely, J., Naturwissenschaften, 1962, 49, 610.

2) Kulesár, A. \& Kulesár-Gergely, J., ibid., 1963, 50, 306.

3) Kaufmann, C., Beitr. path. Anat., 1953, 113, 253.

4) Kulcsár-Gergely, J. \& Kulesár, A., Naturwissenschaften, 1961, 48, 387. 